\title{
Beyond Genre: Black Elements in Radiohead's "Bloom" or Black Music/White Music, What's the Difference?
}

\author{
Kela Nnarka Francis \\ University of Trinidad and Tobago, John S Donaldson Campus, Trinidad
}

Copyright $\subset 2017$ by authors, all rights reserved. Authors agree that this article remains permanently open access under the terms of the Creative Commons Attribution License 4.0 International License

\begin{abstract}
Today's music scene, perpetuates segregation in music. However, such marketing belies the more permeable boundaries between genres or that elements of "black" music still exist in rock or that "white" elements exist in hip hop. One example of black musical elements in a "rock" song is Radiohead's "Bloom" the first track from The King of Limbs (TKOL) released in 2011. Any Radiohead fan can assert that part of the band's popular and critical appeal is their ability to layer sound, creating textured musical experiences. This architectural sound is taken a step further in "Bloom" which has a West African inspired rhythmic arrangement. Not only does this destabilize boundaries maintained by the marketing machine of the music industry, but it also raises some interesting cross cultural possibilities as to how the song might function. For example, given the multiple functions of West African music as political/social/spiritual productions, what insights might one gain by analyzing "Bloom" as a spiritual/psychic experience, especially from an African world view? This paper will examine the structure of "Bloom" using J.H. Kwabena Nketia's explanation of West African composition theory and explore the spiritual experience of "Bloom" using Wole Soyinka's theory of the "fourth stage" and the Bantu philosophy of vital force to illustrate the artificialness of the categories into which we place music and cultures.
\end{abstract}

Keywords Radiohead, Music, Polyrhythm, Race, Spirituality, Ritual, Community Ritual

\section{Introduction}

Recently, while manning the karaoke booth in a local bar, I was playing one of my favorite playlists while the bar was slowly filling with patrons ${ }^{1}$. A young man came through the door with his girlfriend in tow and made a beeline for me. He

1 "Alternative Dance Party" features Radiohead, Arctic Monkeys, Muse, Blur, White Stripes, The Ting Tings, M.I.A., and others. leaned over and asked me, one black person to another, "Don't you have any Caribbean music or just black music instead of all this white stuff?" I half expected that question, so I replied calmly "This is black music. We invented it. The very term 'Rock and Roll' is African American slang." He rolled his eyes "Aw Man, why you gotta go back to origins?" and led his girlfriend out of the bar. I have experienced such exchanges far too frequently in the US, and each encounter highlights two concerns. The first relates to the underlying causes of the young man's ignorance of his own cultural history and his disregard for "origins"- the education system, as a whole, still struggling with racial/cultural inequalities in terms of content and orientation, and what Ralph Ellison terms "a deadly struggle with time, with history" (Ellison 250), a willingness to ignore history. The second concern is the very notion that music can be segregated, deemed white or black. While education or lack thereof contributes to the young man's ability to a-historically and glibly proclaim one type of music as black and another as white, this musical segregation results from longstanding practices in the music industry-appropriation and marketing.

\section{Race, Marketing, and the Artificial Divide}

Amiri Baraka discusses these practices in Blues People: Negro Music in White America (1963) as he attempts a comprehensive analysis of the Blues as a socio-political vehicle.[1] Tracing the history and development of jazz in America from "race music" to high art, Baraka aligns various forms of jazz and blues with race and class divisions. Ellison critiques Baraka's argument stating that "his theory flounders before that complex of human motives which makes human history" and that the "concord of sensibilities" which has been defined as the meaning of culture, allows for much more variety than Jones would admit."[1, 2] Rather than the rigid boundaries of Negro music and white music, class and race, that Baraka portrays, Ellison argues that 
"Negro musicians have never, as a group, felt alienated from any music sounded within their hearing, and it is my [Ellison's] theory that it would be impossible to pinpoint the time when they were not shaping what Jones calls the mainstream of American Music" and that the Negro has influenced American culture "far too long" to be considered outside of the mainstream culture.[2] Ellison's critique highlights the undercurrent of Baraka's theory, for while Baraka's discussion tends towards accusations of a middle class mid-brow agenda to dilute "Negro music" and divest it of emotional validity, what is interesting about his argument is the acknowledgement that American popular music is Negro music, or at the very least a version of Negro music.[1,2] Further, Baraka's argument reveals the interconnectedness between what he assumes to be dilutions and corruptions of African American music forms played by white musicians and the newer forms of jazz and blues which respond to these dilutions.[1,2] For both Baraka and Ellison, the young man's refusal to go back to "origins" and acknowledge the Black roots of so-called white music would be, at the very least, disheartening. Whether African Americans were derisive about "white versions" of their music or more liberal and accepting of imitation, there would have been little doubt in the minds of the majority of Blacks that it was a form of their music, no matter the level or extent of appropriation, and despite the fact that white musicians were marketed as the king of swing, or true jazz experts. This is also true of Rock and Roll where music made popular by African American artists were re-recorded by white groups and promoted more aggressively than the originals.

In Bud Newman's 1985 news article in honor of Black Music History month, "Black Artists make White Singers Big; Black Music Bigger," Newman discusses one of the most overt examples of appropriation and marketing. In the period 1955-56, many "raucous rhythm and blues artists" were covered by white acts such as the Crew Cuts and Pat Boone. These covers were, as Newman puts it, "lifeless versions which cautious record companies felt were more palatable to white listeners." [3] Newman goes on to mention Little Richard at first being angry with Boone's covers because they undermined Little Richard's sales; however, Richard realized that "'By them being white, they made the door bigger for me' [Richard]" and as the article illustrates, the door was widened for R\&B in general.[3]

The marketing aspect here is pretty straight forward, while America was still battling segregation and open racism (there would be 9 years between 1955 and the passage of the Civil Rights Act) it would seem difficult to push Black music in the mainstream market. This is by no means a new fear. Billboard replaced the label "race music" in its charts with Rhythm and Blues in 1946. As Newman points out, up until the 1950s, such music only played on Black Music stations.[3] Keir Keightly also asserts that "Billboard had ranked 'race' and then 'rhythm and blues' hits under their own headings since the 1940 s, because the separate pop and rhythm and blues carts were understood to describe two racially distinct markets." [4] While the growing popularity of acts like Little Richard, Chuck Berry, Ray Charles, Aretha Franklin, and the explosion of Motown eclipsed the "whitening" practice by the early sixties, the separation of genres, a reflection of the social reality of Jim Crow laws and segregation, was maintained through labeling ${ }^{2}$ Newman also credits acts like Bill Haley and the Comets (1955) and Elvis Presley (1957) with introducing undiluted rock and roll to white audiences. Presley's covers, according to Newman, retained the "power and punch" of the originals.[3] Keightly, however, argues that it is "primarily the institutional demand for new material and novelty sounds," rather than any altruistic push for integration or social change from the listening audience, that facilitated the "crossover" successes of some African American performers, and insists that it is "equally important to recall that throughout the 1950s it is white appropriations and hybridizations of 'black' musical styles that sell the most records overall." [4]

More interestingly, Newman's article suggests a definition for "appropriation" in music and allows me to make a distinction between adoption and appropriation. Appropriation in music not only involves the commandeering or seizing of a musical form, but also subtracting the "frantic" and "fevered" aspects of the music-aspects which represent a minority's cultural response to socioeconomic oppression.[3] Such responses are not protest per se, but defiant celebrations of life. However, rather than add any depth, causing the artist and his or her audience to communicate intangibles, the music is made "safe" and "palatable," what I would term inert. Something seems to go missing. Adoption on the other hand, as with the Comets (for example), means taking on a musical form and adding something resonant from the artist - a twist or cultural specificity, even the dreaded word "authenticity." An Elvis Presley song, cover or original, bears the stamp of Presley - an indelible Presley-ness that is not readily articulated or empirically measured.

The industry insiders' fear of the un-marketability of African American music can be aligned to Simon Frith's definition of Pop music (as opposed to popular music).[5] According to Frith, "Pop is not driven by any significant ambition except profit and commercial reward. Its history is a history of serial or standardized production and, in musical terms, it is essentially conservative." [5] While applying the term Pop as a genre might be anachronistic in a discussion about the appropriation of African American and other marginalized music by white executives in the sixties, the underlying conservative ideology of Pop in the face of a racially segregated market elucidates the industry's assumptions about the marketability of un-diluted rhythm and blues. Frith also states of Pop music that it "does not have a specific or subcultural communal market/culture. It is designed to appeal to everyone" [5], suggesting that Pop

2 Keightly asserts that the separate genres reappeared with the British invasion and the rise of soul music.[4] 
music should have universal appeal. However, this universal appeal, as exemplified by the industry moguls, is rooted in white middle class aesthetics and sensibilities. Baraka's chagrin, his distaste for the appropriation of jazz, in part, stems from the paradox of such an exclusionary universality. Further, that this appeal is determined "from on high (by record companies, radio programmers and concert promoters) rather than being made from below" also suggests that the corporate structure of the music industry is complicit in promoting cultural segregation (or a one-way flow of cultural adaptation/appropriation).[5] Keightly de-mythologizes Rock music, dismantling the idea of rock as inherently anti-mainstream or fringe or authentic, by highlighting the white patriarchal underpinnings of the concept of rock music and the construction of its myth.[4] As he points out, the general belief that rock and roll all but died in 1959 before being resurrected with the British invasion does more than reinforce "the sense of rock as a revolutionary rupture"; it also devalues the contributions to popular music by non-white and non-male performers, song writers and industry insiders.[4] Keightly insists that there "is no conspiracy here" before analyzing the privileging of male-ness as in the rock aesthetic and ideology which is codified in 'gendered terms, so that 'soft,' 'sentimental,' or 'pretty' become synonyms for insignificance, terms of dismissal, while 'hard,' 'tough,' or 'muscular' become descriptions of high praise for popular music".[4] It is significant that gendered language is also associated with codifying race, colonialism, and imperialism (where non-whites and foreign landscapes are feminized). At the same time, Keightly aligns rock with Pop stating that "[f]or all of rock's appropriation, modification, or outright theft of African-American, agrarian, or working-class musical cultures, it is not itself a form of cross-over, nor a subculture incorporated by the dominant culture, nor a counter culture".[4] Rather, rock is a "mainstream phenomenon operating at the very center of society."[4] In both pop and rock, the notion of appropriation remains tied to race and class, allowing for the political marginalization of the innovators or sources/inspirations for music consumed by the "mainstream"-privileged-white teenage audience. Baraka, Ellison, Newman, Keightly, and Frith's examinations of the politics of popular music reminds one of the power and influence of what scholars no longer dismiss as trivial. Such examinations also open avenues for discussing the cultural unities between otherwise segregated popular culture productions. [1-5]

Today's music scene, rather the industrial marketing mechanisms orchestrating the music scene, perpetuates this segregation in music. This segregation is as integral a part of the larger issues of race and equality in society as housing equality, job equality, and education equality debates, a constant reminder of the socio-economic struggles faced by people of African descent however obfuscated by marginal (but well publicized) successes. While it is all right, and profitable, for white suburban youth to enjoy and consume hip-hop, R\&B, Jazz, Blues, Reggae and so forth, and equally (though seemingly less prevalent) for black youth to enjoy rock in its various forms, these musical forms are still marketed as black or white, so much so that some black teens into Goth, Rock, Punk, and other "white" genres might relax their hair (more noticeably boys) and/or wear contacts. However, such marketing belies the more permeable boundaries between genres or that elements of "black" music still exist in rock or that "white" elements exist in hip hop. One example of black musical elements in a "rock" song is Radiohead's "Bloom," the first track from The King of Limbs (TKOL) released in 2011. [6]

Any Radiohead fan can assert that part of the band's popular and critical appeal is their ability to layer sound, creating textured musical experiences. Further, it is the quality of these layers - intricate bass lines, discordant but complimentary guitar riffs, complex drum beats-which makes Radiohead so influential. On their album, The King of Limbs, they take this architectural sound a step further by layering the percussive elements (two standard drum kits, an electronic drum kit, extra snare and tom-tom drums). Chuck Arnold in a review of the album published in People magazine states that "[1]like most Radiohead albums its spell sneaks up on you upon repeated spins as you lose yourself in all of the layered atmospherics" and highlights the "polyrhythmic structure of tracks like ['Bloom'] and "Ferral"..[7] David Fricke, in his article "Radiohead Reloaded," describes the album as a "lush tangle of samples, drum loops, and glassy vocal reveries".[8] This layering, polyphonic atmosphere is especially evident on the first track "Bloom" which has a West African inspired rhythmic arrangement with an anchoring beat at the core and an overlaying of related beats and rhythms. Not only does this destabilize boundaries maintained by the marketing machine of the music industry, but it also raises some interesting cross cultural possibilities as to how the song might function ${ }^{3}$. For example, given the multiple functions of West African music as political/social/spiritual productions, what insights might one gain by analyzing "Bloom" as a spiritual/psychic experience, especially from an African world view? This paper will examine this spiritual experience of "Bloom" using Wole Soyinka's theory of the "fourth stage" to illustrate the artificialness of the categories into which we place music and cultures. [9]

\subsection{West African Rhythms}

The incorporation of "world music" elements into rock music is by no means a new phenomenon ${ }^{4}$ Beatle's songs

3 Radiohead are no strangers to flouting conventional music industry wisdom as one the most influential "indie" bands on the scene and releasing their last two albums over the internet.

4 Caspar Llewellyn Smith in his article "I'm with D'Banj" in The Guardian published 23/6/12 describes the growing interest of African Pop music in the UK and quotes Rickie Davies who "runs a website promoting Afro beats in the UK" as saying that "No one talks about this as if it's 'world music' [...] or alien to the culture here." 
such as "Tomorrow Never Knows" from Revolver (1968) and "Within You Without You" on Sgt. Pepper's Lonely Hearts Club (1968) use sitars in their instrumentation.[10,11] Vampire Weekend's "Cape Cod Kwassa Kwassa" from Vampire Weekend (2008) and "I think Ur A Contra" from Contra (2010) draw heavily upon South and West African music respectively.[12,13] In both bands' cases, these added elements and influences are easily distinguishable and involve the intermingling of "world music" sounds. What is interesting about "Bloom" is that it employs West African rhythmic principles rather than sounds. Instead of using djembe drums or wooden xylophones, for example, the song is structured similarly to West African music using a multilinear rhythmic pattern.

According to J. H. Kwabena Nketia in The Music of Africa (1974), the "melodic and polyphonic forms utilized in African music derive their dynamic qualities from the rhythmic framework within which sound materials are organized" and that "since African music is predisposed towards percussion and percussive textures, there is an understandable emphasis on rhythm".[14] In "Bloom" this emphasis on rhythm translates into the layered texture of the percussive instruments as well as the rhythmic patterns of guitars and bass. The three percussive instruments, electric drums played by Clive Deamer, full drum kit played by Phil Selway, and the half-kit played by Jonny Greenwood form the core of the song's multilinear pattern. $[6,14]$ Each drummer maintains a specific rhythm that overlaps, creating a more complex sound. These rhythms, however, all relate to what Nketia describes as a "fixed time span, which can be broken up into an equal number of segments or pulses of different densities".[14] For example, let us assume that "Bloom" uses a "duple rhythm"- based on a time span divided into multiples of two- the electric drum kit uses a fast pulse ( 8 pulses), the half-kit a moderate pulse (4 pulses), and the full kit a fast pulse. Further, with the half-kit, the duple rhythm is also additive where, as Nketia notes, "instead of note groups or sections of the same length, different groups are combined within the time span".[14] For example, if the rhythm is duple, and the half-kit is the moderate pulse ( 4 pulses), then it can be split in $1+3$ or $3+1$ pulse patterns rather than $2+2$. While the electric drums use a fast pulse, its function is closer to the idiophone (clapping, canastas) in keeping the time line, a "guideline which is related to the time span" by "externalizing the basic pulse".[14] This externalized basic pulse can have a "more complex form" as is the case with the electric drum kit.

In addition to the rhythmic structures themselves, the structure of "Bloom" also exhibit two principles of African rhythmic arrangements that Nketia identifies as grading and spacing.[14] According to Nketia, "rhythms to be combined in [a multilinear rhythmic organization] must be graded in density or complexity in relation to the role of each part as accompanying, response, or lead instrument".[14] With "Bloom" each accompanying instrument, guitars and bass, maintain a distinct rhythmic and melodic pattern, Thom
Yorke plays a six-note melody, Ed O’Brian a two-note melody, and Colin Greenwood a complex bass line. Further, each instrument is spaced where the "interlocking part may be arranged in such a way that by their overlapping they form a resultant pattern".[14] Specifically, with "Bloom" these patterns are spaced "in terms of points of entry" creating an "interplay of polyrhythms".[14] In the live version, the first rhythm is the electric drum kit around which the other rhythms are structured. The second rhythm is Yorke's guitar (replacing the opening piano phrase of the album version), followed by O'Brien's guitar, Selway's full-kit, J. Greenwood's half-kit, C. Greenwood's bass, Yorke's vocals, and finally the horn section ${ }^{5}$.[6] Along with grading and spacing, the different tonal qualities of the instruments allow each to "stand out clearly in the form of little "tunes" while contributing to an overall sound.[14] One should also consider that Radiohead's adaptation of the multilinear rhythmic organization of West African music to European instruments is also influenced by the band's interest in jazz. As Baraka states: "The most apparent survival of African music in Afro-American music are its rhythms: not only the seeming emphasis in the African music on rhythmic, rather than melodic or harmonic qualities, but the use of polyphonic or contrapuntal rhythmic effects".[1] However, while Radiohead's use of European instruments—bass, guitar, and military drum kit- to produce a polyrhythm can be attributed to jazz (very much an American, New World, United States music), the presence of three percussive elements suggests a more recent influence of African derived practices. (Even so, this is "splitting hairs" as the African influence on jazz and vice versa makes singling out a specific source of style increasingly difficult.)

\section{2. "Bloom" and the "Fourth Stage"}

While classifying "Bloom" as African music would be overreaching and not the point of this paper, these African elements in the song open avenues of inquiry that may be ignored or underexplored when analyzing rock music. If "Bloom" employs African rhythmic principles, and African music is usually associated with spiritual processes, whether secular or devotional, political or party/dance, is it possible to analyze "Bloom" as a spiritual experience? This is not to claim that Radiohead deliberately engages a spiritual process through the song, or to suggest that Western music does not function on a spiritual or psychic level. On the contrary, as modern Western music is indebted to Afro-American musical forms which, in turn, are indebted to the rhythm and pulse of African music, then the music we hear today has maintained, at the very least, the potential to function spiritually. This spirituality is often carried by the drums. In the case of calypso and other African derived musical forms in the Caribbean, the bass, played as a rhythmic or percussive

5 On the album version, the order is piano, guitar, electronic drum, drum, bass, vocals and horns. 
instrument, tends to emanate the spiritual message. As Baraka asserts, Africans "used drums for communication [...] by the phonetic reproduction of the words themselves".[1] Even though Baraka later argues the religious or spiritual significance in African American music was dropped by succeeding generations adjusting to Christian and American life - a stance I disagree with, especially as the blues elicits responses contrary to the sadness expressed in lyrics, tone, mood, and sound - if the drum communicated speech and given the holistic approach African cultures have or had to life, the non-separation of the spiritual from the secular, then even if the language is beyond a tangible translation for the average listener, the spiritual message is there. However, unless Western music is religious, either through content or context, analytical focus does not engage the spiritual function of the music. Instead, analyses discuss the emotional content and context of the music. For example, rather than analyzing whether a minor chord arrangement might lead to a submergence of consciousness into another state, the discussion centers on the emotional impact of minor chords (usually associated with sadness or somberness). Neither focus is exclusionary, indeed, they will overlap.

Jazz is a prime example of how a western secular musical form also maintains a spiritual function. In "Jazz Performance as Ritual: The Blues Aesthetic and the African Diaspora" Travis Jackson also discusses jazz's ritual function in society. Like Baraka and Ellison, Jackson links the blues and jazz and asserts that "one of the primary forces driving the creation and making possible the interpretation of African American music and, in particular, jazz is concerned both with the blues as an aesthetic or sensibility and with the performance as a sacred, ritual act".[16] The musicians are heavily invested in the ritual function of the music. According to Jackson the musicians he interviewed are concerned with "having an individual voice" as well as "being able oneself to 'bring something to the music'; creating music that is 'open enough' to allow other musicians to bring something" and "being open for transcendence to the 'next level' of performance, the spiritual level".[16] As Jackson states, the "openness" advocated by the musicians "is a way of dealing with the materials at hand (structure, sound, skill, personalities, performing context) and fashioning them into viable and meaningful expression".[16] This interplay is necessary to facilitate players reaching what one "might refer to as trance or possession" where the "performance takes place seemingly on its own".[16] When each performer "successfully synthesize[s] and work[s] with all the materials of a performance"-adjusting in each element of space place, and collaboration - "a performance is likely to proceed to the next level".[16] Further, each player, by bringing "something" to the performance injects "soul" into the music. This "soulfulness" as Jackson articulates is linked to the "blues aesthetic" which is "founded in various forms of activity" in African American life and culture-religious, musical and other cultural practices.

\subsection{1. "Soulfulness"}

While Jackson references the concept of "soulfulness," he does not offer a working definition of "soul." This is in part due to the ethereal or metaphysical aspects of "soul" which do not allow for a concrete definition. At best, Jackson indicates that infusing "soul" into a performance depends on the appreciation if not full participation in African American culture-which is a more accommodating stance than Baraka's.[1,16] However, most definitions of soul imply a racial exclusivity. For example, according to Leonard $\mathrm{E}$ Barrett "in the true world of Black experience, the word [soul] conveys a potent and very special quality of feeling that is unknown to those who are not Black" and that "Soul' signifies the moral and emotional fiber of the Black man that enables him to see his dilemmas clearly and at the same time encourages and sustains him in his struggles".[17] In his Black Arts Movement zeal, Barrett makes the same assumption as Baraka-that "soul" and "soulfulness," the true essence of jazz and blues, is alien to non-Blacks.[1,17] Yet as Barrett defines soul linking it to the concept of force-"strength, power, intense effort and a will to live"- he leaves open the possibility that any community with such an "intense effort" and "will to live" in the face of trauma, regardless of race, will develop "soul-force," what he describes as "that power of the Black man which turns sorrow into joy, crying into laughter, and defeat into victory. It is patience while suffering, determination while frustrated and hope while in despair" (emphasis added).[17] Despite Barrett's reactive militancy, itself an example of the "compartmentalizing habits of thought" [9], his definition of soul recalls Soyinka's claims for the universality of the "fourth stage" creative process: any culture (and by extension any subset or individual of that culture) that has experienced trauma formulates a ritual to access the "fourth stage". $[9,17]$ If the modern trauma of the globalized industrial complex society is the suppression of human expression in favor of materialism, this society will reformulate ritual and ritual activity to ensure creative solutions to survive such trauma.

Several of the reviews of The King of Limbs refer to the album as an emotional journey. Marsha Vdovin in Electronic Musician states that the "complex structure of subtle production [...] takes the listener on a tour of emotional realms".[18] Jon Dolan in Rolling Stone states that the album "follows strange logic down alleys it has no interest in coming out of" and that "for the most part" the album "lingers in states of emotional and physical in-between-ness-blooming, diving, flirting, floating, falling".[19] Simon Vozick-Levinson in Rolling Stone calls the album version of "Bloom" "cold-blooded" and that the song "make[s] way more sense" live while Fricke notes the "laptop-built ambience of "Bloom" is invigorated when performed live. $[8,20]$ Arnold comments that "Bloom" is "a trippy, almost mystical incantation that careens and 
caresses".[7] Even though the authors attempt to capture their emotional response to "Bloom," Arnold's assessment of "Bloom" as "almost mystical incantation" (he also refers to "Feral" as "a mesmerizing African-tinged thriller") and Dolan's description of the album lingering in "states of [...] in-between-ness" suggest a deeper psychic/spiritual significance of the song, especially when coupled with the spiritual nature of many forms of African music.[7,19] Also if one compares "Bloom" to "Harry Patch (in Memory of)" with its melancholy string arrangement and Yorke's choir-boy voice juxtaposing the innocence of childhood with the horrors of war, the idea that "Bloom" functions on a spiritual more than emotional level seems more tenable. [6,21]

\subsubsection{The "Fourth Stage"}

As with jazz and soul, one possible explanation for how and why "Bloom" "careens and caresses," "follows strange logic," and hovers in a state of "in-between-ness" is Wole Soyinka's theory of the "fourth stage".[9] According to Soyinka, artistic creativity involves a psychic and spiritual descent into, traditionally, the underworld or chthonic realm which he terms the "fourth stage." Soyinka states that the chthonic realm is "the seething cauldron of the dark world will and psyche, the transitional yet inchoate matrix of death and becoming", the essence of which is "contained and mystically expressed" by the "collective being" of the chorus of traditional Yoruba tragedies.[9] The artist must journey across this transitional gulf through the fourth stage, and this trespass of the chthonic realm results in cosmic creativity.[9] There is a direct relationship between this "fourth stage" process and music which often has a ritual function. If "Bloom" is an "incantation," and if one considers that the band acts as dramatic chorus, it is possible to explore the song as both the result of the band experiencing (and re-experiencing) the fourth stage and initiating a fourth stage experience in listeners. In Fricke's article, Yorke claims that figuring out how to play the songs on King of Limbs live "creates an energy that we [Radiohead] want to pursue" and Deamer in the same article states that "every time we play, it [the music] grows. Something slightly different can happen". [8]

This is not to claim that the band intentionally engages the "fourth stage," however, as many musicians attest, they may have experienced a process similar to what Soyinka describes as the "fourth stage".[9] In my dissertation, "African Masking Process: Re-Interpreting Mask and Mas' in Six Anglophone Texts," I expand upon Soyinka's theory to map the process of accessing the "fourth stage," outlining four phases of the process - opening, entering, traversing, and exiting.[22] At the point where playing "Bloom" live creates energy and grows, Radiohead has already opened and entered the chthonic realm. For the audience, the process is just beginning, for the band, as the main actors are opening the "fourth stage" and leading the way in. The atmospheric and incantatory nature of "Bloom," rather than being "cold-blooded" is otherworldly, leading the imagination outside of the human condition, both lyrically and musically. Adding to the atmospheric harmonics of the multilinear rhythmic organization of "Bloom" live, the lyrics invite the listener to float into a mixture of space and ocean.[6] By the second verse, the audience has entered a strange space and is traversing it by "moving out of orbit," to encounter giant turtles and jellyfish rendered unfamiliar by their context (outer space). By merging ocean life imagery and outer-space imagery, the lyrics produce a space where several forms of being (human and alien) interact - a "fourth stage."

\subsubsection{Concert as Communal Ritual}

The possibility of interpreting "Bloom" through Soyinka's theory of the "fourth stage" opens up the possibility of investigating the effects of music on community without dismissing it as frivolous or a palliative pastime. What Soyinka describes is a communal ritual experience meant to reconnect participants with a larger-than-life force, a larger-than-life grasp of humanity and its place in the universe, a form of spiritual or psychic catharsis.[9] If we consider music and communal musical performances from an African perspective, communal performances have these added functions. As Nketia notes:

The performance of music in such contexts [social gatherings, rites, ceremonies, etc.], therefore, assumes a multiple role in relation to the community: it provides at once an opportunity for sharing in the creative experience, for participating in music as a form of community experience, and for using music as an avenue for the expression of group sentiments.[14]

In an increasingly fractured and individualistic society, these concerts allow us to gather as a community in the way Patrice Malidoma Some defines it: "Any group of people meeting with the intention of connecting to the power within is a community". [23] In this context, if we contemplate the multiple functions of any song, exemplified here by "Bloom", there are at least two purposes forming a community at a concert. The first is spiritual release. In keeping with Soyinka's theory, the spectators watching the human celebrant(s) enter the chthonic realm participate in the energy such a breach produces.[9] This energy resonates below the cognitive surface, leading to a release, more than emotional or mystical, a release felt deep in an indescribable part of one's being. Gordon Rohlehr, for example, in his essay "Sound and Pressure," describes the effects of ska on the underprivileged classes in Jamaica in a similar tone.[24] According to Rohlehr the people found ska to be "a release from the daily inferno of their harsh lives".[24] He compares the social function of ska to that of the Blues, describing the latter as "complex-a mixture of submission and rebellion".[24] Rohlehr's word choice addresses motivations deeper than emotional, especially as he cites the Afro-centered spiritual influence of the musical forms, and 
correlates with Soyinka's destructive (submission) and creative (rebellion) forces in the fourth stage.[9,24] The communal aspect of these performances also allows for spiritual (re)connection with members of the community. According to Kimbwande Kia Bunseki Fu-Kiau in African Cosmology of the Bantu-Kôngo (1980) "Life is fundamentally a process of perpetual communication; and to communicate is to emit and receive waves and radiations. This process of receiving and releasing or passing on is the key to human being's game of survival".[25] Thus, within the community of a concert, this communicated energy is amplified in a closed circuit-when the band on stage releases cosmic creative energy, it is communicated to the audience which triggers a release of cosmic energy which is communicated to the band. Performing such communal rituals where each participant builds positive energy could offer a corrective to the oppressive and isolating aspects of modern capitalist society, as Malidoma states: "in the formation of the community is the possibility of doing together what is impossible to do alone. This acknowledgement is also an objection against the isolation of individuals and individualism by a society in service of the Machine".[23] Performing such a communal ritual with some awareness, could serve as a template each participant could apply to his or her life long after the concert is over.

\section{Conclusions}

Analyzing a "little rock song" like Radiohead's "Bloom" through an African philosophical lens underlines the artificial rigidity of musical boundaries maintained by the music industry. It also highlights the fluidity of music as expression and experience. Radiohead can be considered genre-less, and a cursory glance at any "office chart" listed on their website confirms that their influences are wide ranging and often pleasantly surprising. Further, the influence they exert on other genres is equally pleasantly surprising, from jazz, reggae, to hip-hop. The limiting notion of describing music as black or white denies this communal performance and obscures the spiritual and political benefits that music might provide. For the audience, participation in the energy the band produces, the experience of the process, leads to a release, more than emotional or mystical, a release felt deep in an indescribable part of one's being, allowing one to move beyond race to appreciate humanity. Black music, white music, what really is the difference?

\section{REFERENCES}

[1] A. Baraka. Blues people: Negro music in white America, William Morroe and Co., New York, 1963.

[2] R. Ellison. Shadow and act, Quality Paperback Book Club, New York, 1964.
[3] B. Newman. Black artists make white singers big; Black music bigger, The Courier, 1985, Online available at https://news.google.com/newspapers

[4] K. Keightly. Reconsidering Rock. In: S. Frith, W. Straw, and J. Street. The Cambridge Companion to Pop and Rock. Cambridge University Press, Cambridge, 2001. 109-42.

[5] S. Frith. Pop music. In: S. Frith, W. Straw, and J. Street. The Cambridge Companion to Pop and Rock. Cambridge University Press, Cambridge, 2001, 93-108.

[6] Radiohead. Bloom. The King of Limbs. XL Records. 2011

[7] C. Arnold. The King of Limbs, People. Vol. 75, No. 10, 47, 2011.

[8] D. Fricke. Radiohead Reloaded. Rolling Stone. No.1142, 17-8, 2011.

[9] W. Soyinka. Myth, Literature and the African World. Cambridge U P, Cambridge, 1976.

[10] J. Lennon, P. McCartney. Tomorrow Never Knows. Revolver. Parlaphone, 1966

[11] G. Harrison. Within You and Without You. Sgt. Pepper's Lonely Hearts Club Band. Parlophone, 1967.

[12] Vampire Weekend. Cape Cod Kwassa Kwassa. Vampire Weekend. 2009.

[13] Vampire Weekend. I think Ur a Contra. Contra. 2010.

[14] J.H. K Nketia. The Music of Africa, Norton, New York, 1974.

[15] C. L. Smith. I'm with D'Banji, Online available from http://The Guardian.co.uk .

[16] T. Jackson. A. Jazz Performance as Ritual: The Blues Aesthetic and the African Diaspora. The African Diaspora: A Musical Perspective, Routledge, New York, 23-82, 2001.

[17] L. E. Barrett. Soul-Force: African Heritage in Afro-American Religion, Anchor Press, New York, 1974.

[18] M. Vdovin. Listen to Playlist. Electronic Musician. Vol.27, No.5, 40, 2011.

[19] J. Dolan. The King of Limbs. Rolling Stone. No.1126, 61-2, 2011.

[20] S. Vozick-Levinson. Radiohead: The King of Limbs Live From the Basement. Rolling Stone No.1148, 57, 2012.

[21] Radiohead. Harry Patch (in Memory of). 2010

[22] K. N. Francis. The African Masking Process: Re-Interpreting Mask and Mas' in Six Anglophone Texts, LAP, Germany, 2015.

[23] P.M. Soma. Ritual: Power, Healing, and Community, Penguin Group, New York, 1993.

[24] G. Rohlehr. Sounds and Pressure, My Strangled City, Longman Trinidad Ltd., Trinidad, 1992, 86-94.

[25] K. K. B. Fu-Kiau. Tying the Spiritual Knot: African Cosmology of the Bântu-Kôngo, Principles of Life and Living, Anthelia Henrietta Press, Canada, 2001. 